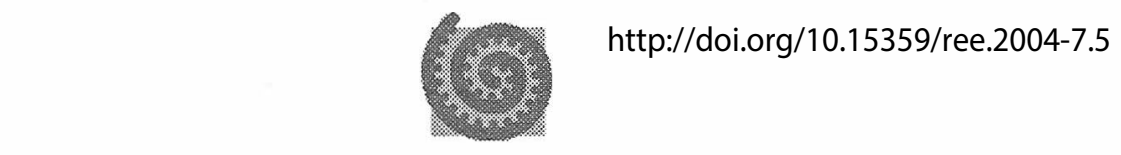

\title{
LA INTELIGENCIA EMOCIONAL EN LAS INSTITUCIONES EDUCATIVAS
}

Ileana Vargas J.*

Se pretende con el siguiente artículo reflexionar acerca de la importancia de la inteligencia emocional y cómo esta puede ser un instrumento útil para la labor del maestro (a) qué es y cuáles son los componentes, así como algunas estrategias útiles para implementar dentro del salón de clases. Finalmente en el artículo se señala cómo impactan en las organizaciones, especialmente, en lo que tiene que ver con cambio organizacional, resolución de conflictos y liderazgo.
The following article invites the reader to reflect on the importance of emotional intelligence and how it may be a valuable tool for the teacher (a) what it is and which are its components, as well as some useful strategies to be introduced in the classroom. Finally, the article indicates how they cause an impact in the organizations, especially in terms of organizational change, dispute resolution and leadership.

* Licenciada en Educación Preescolar, con una Maestría en Administración Educativa de la Universidad de New Mexico, Estados Unidos, Directora de la División de Educación para el Trabajo. 


\section{¿Por qué es importante hablar y conocer la inteligencia emocional?}

Hoy en día las personas y muy especialmente los docentes, se ven envueltos en horarios de trabajo muy rígidos, cargados de tareas, responsabilidades múltiples y algunas funciones que de alguna manera van socavando las buenas relaciones humanas. Es así como nace una nueva forma de entender y comprender las relaciones humanas, especialmente con lo que se denomina inteligencia emocional, la cual no se limita a la vida privada de las personas sino que se puede aplicar también a la vida profesional, y es aquí en donde el artículo hace énfasis.

Se define la inteligencia emocional como la habilidad de percibir, entender y aplicar efectivamente el poder de las emociones para inspirar confianza, iniciativa, energía, creatividad y motivación en los demás (Cooper, 2003). Para Goleman es la capacidad para reconocer sentimientos en sí mismo y en otros, siendo hábil para reconocerlos al trabajar con otros. De estas dos definiciones, surge la siguiente interrogante:

¿Cómo puede una persona utilizar su inteligencia emocional en el ambiente de trabajo?

Primeramente, descubriendo las capacidades y cualidades de las personas para estimular el alcance de metas, el secreto está en desencadenar esas capacidades en la gente, a permanecer tranquilos en momentos de estrés, a tomar mejores decisiones, a valorar las capacidades individuales de la gente que está a nuestro alrededor, a no alabar a las personas en grupo, sino a descubrir las fortalezas de cada individuo. Es decir, los individuos al aplicar la inteligencia emocional no solo están beneficiando el campo laboral, también, en lo personal, porque empieza a fijarse más y mejor en las necesidades y sentimientos de la gente con la cual labora, a escuchar mejor a sus interlocutores y a lograr que la gente se comprometa con lo que hace. De los ocho tipos de inteligencia de los que habla Howard Gardner, dos se refieren a nuestra capacidad de comprender las emociones humanas, la inteligencia interpersonal es una de ellas y está relacionada con nuestra capacidad de entender a los demás, la otra es la inteligencia intrapersonal, esta está determinada por nuestra capacidad de entendernos a nosotros mismos. Daniel Goleman agrupa ambos tipos de inteligencia bajo el nombre de inteligencia emocional, esta es la capacidad de comprender nuestras emociones y las de los demás, la inteligencia emocional determina, por ejemplo, nuestra capacidad de resistencia a la frustración, a la confusión, es decir, a la manera de reaccionar ante la adversidad, quiere decir que la capacidad de aprendizaje está, por tanto, íntimamente ligada al uso que hagamos de la inteligencia emocional.

Corresponde al maestro (a) conocer los elementos de la inteligencia emocional y aplicarlo, pues de esa manera su trabajo se verá más beneficiado en el trato con los niños (as), con los padres de familia, en sus relaciones con los demás etc. 
Cuando se habla de inteligencia emocional no significa estar siempre contento o evitar problemas, sino mantener un equilibrio, poder reconocer los malos momentos, aceptar los propios sentimientos sin dañarse ni dañar a los demás, en el trabajo cotidiano con niños, con adolescentes, se hace necesario conocer y tratar de aplicar la inteligencia emocional, especialmente para los maestros y profesores que conozcan y puedan emplear la inteligencia emocional.
El control emocional, por lo tanto, consiste en analizar las situaciones emocionales con el fin de controlarlas, Reigh (2004) comenta que la emocionalidad (situación emocional) puede dividirse en lo que el trabajador experimenta y en lo que expresa, es decir, el control emocional va en dos sentidos; controlar lo que se siente y controlar lo que se expresa.

Es importante destacar que desde hace casi cien años el coeficiente intelectual (CI) es el medidor de la inteligencia más usado, a pesar de que calibra solo unas cuantas habilidades de nuestra mente (en particular las matemáticas y las ver-

bales). Según algunos autores, este coeficiente solo es responsable del veinte por ciento de la verdadera inteligencia, de la capacidad de desenvolverse con éxito y ser feliz. Según estadísticas realizadas en los Estados Unidos, un alto coeficiente intelectual de un alumno universitario no es garantía de éxito profesional futuro ni de una vida satisfactoria, plena y equilibrada.

Cuando se habla de inteligencia emocional no significa estar siempre contento o evitar problemas, sino mantener un equilibrio, poder reconocer los malos momentos, aceptar los propios sentimientos sin dañarse ni dañar a los demás.

Seguidamente se decriben las emociones primarias porque son la brújula que nos indican cómo reaccionamos ante los acontecimientos diarios. Es necesario conocer ¿cuáles son las emociones que los seres humanos poseemos y cómo nos afectan en las relaciones con los demás?

- Ira: Es cuando la sangre fluye a las manos, y de esta forma resulta más fácil tomar un arma o golpear un enemigo; el ritmo cardíaco se eleva, lo mismo que el nivel de adrenalina, lo que garantiza que se podrá cumplir cualquier acción vigorosa.

- Miedo: La sangre va a los músculos esqueléticos, en especial a los de las piernas, para facilitar la huida. El organismo se pone en un estado de alerta general y la atención se fija en la amenaza cercana.

- Felicidad: Aumenta la actividad de los centros cerebrales que inhiben los sentimientos negativos y pensamientos inquietantes. El organismo está mejor preparado para encarar cualquier tarea, con buena disposición y estado de descanso general. 
- Amor: Se trata del opuesto fisiológico al estado de "lucha o huye" que comparten la ira y el miedo. Las reacciones parasimpáticas generan un estado de calma y satisfacción que facilita la cooperación.

- Sorpresa: El levantar las cejas permite un mayor alcance visual y mayor iluminación en la retina, lo que ofrece más información ante un suceso inesperado.

Ahora que se han señalado las emociones primarias, se puntualizarán seguidamente:

\section{¿Cuáles son los componentes de la inteligencia emocional?}

1) Habilidades intrapersonales: la conciencia de uno mismo (el reconocer un sentimiento mientras ocurre) es la clave de la inteligencia emocional. Una mayor certidumbre con respecto a nuestras emociones es una buena guía para las elecciones vitales, desde casarse, por ejemplo, hasta optar entre un trabajo u otra decisión.

2) Habilidades interpersonales: se basa en la capacidad anterior, las personas que saben serenarse y librarse de la ansiedad, irritación o melancolías excesivas se recuperan con mayor rapidez de los reveses de la vida.

3) Automotivación: las personas que saben controlar la impulsividad y esperar para obtener su recompensa cumplen con sus objetivos y están conformes con sus logros, incluye la confianza y seguridad en sí mismo, busca siempre la motivación interna del individuo cómo se siente y cómo se valora y la externa la que brinda el medio ambiente que nos rodea, así como los amigos, familiares, entre otros.

4) Empatía es la capacidad para reconocer las emociones de los demás, saber qué quieren y qué necesitan, es la habilidad fundamental para establecer relaciones sociales y vínculos personales. Se dice que los líderes deben poseer esta habilidad, es decir, tratar de colocarse en los zapatos de los otros.

5) Manejar las relaciones significa saber actuar de acuerdo con las emociones de los demás, determinan la capacidad de liderazgo entre las personas que interactúan entre sí.

$\mathrm{Al}$ respecto Goleman sugiere las siguientes reflexiones:

- Examinar: ¿cómo hacemos las valoraciones?

- ¿Cómo nos sintonizamos con nuestros sentidos?

- ¿Cómo entramos en contacto con nuestros sentimientos?

- ¿Cómo aprendemos sobre nuestras intenciones reales? 
- ¿Cómo prestamos atención a nuestras acciones?

- ¿En qué situaciones hablo conmigo mismo normalmente?

- ¿Cuándo fue la última vez que hablé conmigo mismo?

- ¿Qué tal me trato a mí mismo? ¿Soy amable conmigo mismo o soy duro y desagradable?

- ¿Qué tipo de cosas me digo?

- ¿Cómo podría cambiar mi diálogo interno para que me ayude más?

Este parámetro inicial de autoconocimiento es básico porque nuestra predisposición a una respuesta cortés, o a una expansión incontrolada, depende más de la valoración que hagamos de nuestro interlocutor que del hecho puntual que estamos evaluando.

Sin embargo, debemos tener en cuenta las siguientes consideraciones:

- Que es la valoración y no el comportamiento del otro lo que causa nuestra reacción.

- Ser muy conscientes de que nuestra valoración es solo nuestra.

- Aceptar que las valoraciones están sujetas a cambio.

Además, Goleman afirma que algunos ejercicios personales, tales como anotar, analizar y rehacer mentalmente nuestras autovaloraciones erróneas son vías de desarrollo en esta primera dimensión de la inteligencia emocional.

\section{Dirigir las emociones}

Hemos oído muchas veces "controla tus emociones", y en demasiadas ocasiones nos hemos confundido y, en vez de controlar, lo que hemos hecho es simplemente "ahogar nuestras emociones". Esto es un error porque las emociones no son en sí mismas ni buenas ni malas, la que puede ser buena o mala.es nuestra respuesta. En todo caso, las emociones son las señales que nos permitirán analizarlas para lograr finalmente que trabajen a nuestro favor.

Es interesante destacar el funcionamiento de los componentes de un PC (disco duro, monitor, impresora...), estos son elementos que interfieren unos con otros y que armonizan su funcionamiento para una realización óptima, si un componente falla, todo el sistema falla. En el caso de nuestras emociones, los componentes serían: nuestros pensamientos o valoraciones cognoscitivas, nuestros cambios psicológicos o acciones basadas en la excitación nerviosa y nuestras tendencias comportamentales.

Así, para un buen manejo de este parámetro de la inteligencia emocional necesitaríamos tomar el mando de nuestros pensamientos, dirigir oportunamente nuestras excitaciones nerviosas y llegar a ser buenos solucionadores de problemas, no obstante lo anterior, es difícil de lograr si no nos conocemos a nosotros mismos. 
Por tanto, en la gestión de problemas, es necesario ser muy conscientes de que:

- El problema real no es quién está involucrado. El problema real es cómo respondemos.

- El problema real no es que nos moleste el problema. El problema real es cómo me siento.

- El problema real no es cómo ha ocurrido. El problema real es cuándo lo tratamos de resolver.

Algunas de las pautas a seguir que nos pueden ayudar a realizar esta difícil tarea serían, en primer lugar, comprender la naturaleza de los problemas y posteriormente, interiorizar la idea de que son las respuestas a las situaciones las que causan los problemas.

Es vital admitir, sin embargo, que los problemas son parte normal de la vida y no hemos de sentirnos obsesionados por ellos, cuando los tenemos, la clave no está en negar los problemas, sino en solucionarlos.

\section{Algunos ejemplos para utilizar dentro y fuera del salón de clases}

Seguidamente se exponen algunas formas de intervención que puede emplear el educador para facilitar el conocimiento y dominio de sí mismo:

- Uso de frases motivadoras y diálogos internos constructivos.

- Sentido del humor dentro y fuera del salón de clases.

- Utilizar técnicas de relajación con sus estudiantes.

- Sintonía de pensamientos e interpretaciones positivos.

- Realizar algún tipo de actividad física.

- Emplear dentro del salón de clases algunas técnicas de cómo resolver problemas con los estudiantes.

- Apoyarse en nuestro equipo de personas más cercanas, por ejemplo: amigos, amigas, parientes, etc.

- Tratar de escuchar activamente a nuestros interlocutores.

- Cuando se presenta algún conflicto, tratar de separar las personas de los temas en conflicto.

- Enfocar en intereses y no en posiciones.

- Establecer metas y objetivos precisos de trabajo.

Así mismo, Goleman apunta que un control adecuado de las relaciones interpersonales se basa en dos aspectos: el autocontrol y la empatía, y haciendo 
referencia a una cualidad muy importante para el desarrollo de las personas, agrega que el niño que aprende a aprender requiere tener confianza, curiosidad, intencionalidad, autocontrol, relación, capacidad de comunicación y cooperación; todos estos elementos se deben trabajar dentro del salón de clases.

A medida que las organizaciones cambian y evolucionan, sus líderes se ven en la necesidad de gestionar el impacto de estos cambios sobre los sistemas de valores y creencias de la propia organización y de los individuos que la componen, es decir, se dan dos aspectos que son propios del manejo de situaciones de cambio y transición: uno, es percibir el cambio y, el otro, es gestionarlo. Significa que los directores y directoras de las instituciones educativas deben poseer habilidades de liderazgo para estimular ese cambio y de esta forma asegurarse de que se genera en el ambiente adecuado.

Es indudable que la motivación en este aspecto juega un papel fundamental, ya que los individuos cuando se sienten motivados desean alcanzar un resultado diferente en su ambiente laboral.

Con lo anteriormente anotado surge una interrogante: ¿qué relación tiene este punto con la inteligencia emocional? La respuesta es que las relaciones cobran especial importancia, ya que las organizaciones se desenvuelven en ambientes más competitivos y dinámicos, lo que significa fuertes modificaciones en el estilo de gestión.

El liderazgo inspira y guía a individuos o grupos, es decir, las personas dotadas de esta aptitud articulan y despiertan entusiasmo en pos de una visión y misión compartida, orientan el desempeño de otros y guían mediante el ejemplo, entendiendo la visión como aquella mirada hacia el futuro en la que todos y todas nos comprometemos o alcanzar los anhelos y aspiraciones que se quieren hacer realidad en la escuela, por ejemplo. La misión por otro lado, significa los valores, lo que hacemos, lo que tenemos y responde a la razón de ser de una institución.

Quiere decir que cada aptitud emocional interactúa con las otras, la tarea del líder requiere de una amplia variedad de habilidades personales para poder participar y actuar con elementos propios de la inteligencia emocional, en otras palabras, el director o directora de las instituciones educativas deben conocer estos elementos para poder dirigir las instituciones educativas de la manera más adecuada posible.

Otro elemento es el manejo de conflictos, las personas dotadas de esta aptitud manejan con diplomacia y tacto situaciones tensas y personas difíciles, detectan los potenciales conflictos, ponen al descubierto los desacuerdos y ayudan a reducirlos. Además, de que alientan al debate y la discusión franca. 


\section{Conclusiones}

El uso adecuado de la inteligencia emocional nos ayuda a mejorar las relaciones interpersonales, así como, a manejar situaciones desagradables o tensas. Los problemas son parte normal de la vida, la clave no está en negarlos sino en solucionarlos. Comprender la naturaleza de estos y posteriormente interiorizar la idea de que son las respuestas a las situaciones las que causan los conflictos. Si los maestros (as) inician y aplican los componentes de la inteligencia emocional en sus aulas se podrá asegurar un ambiente más cálido y estrecho entre alumnos y docentes.

Finalmente, los directores y directoras de instituciones educativas deben al menos estar claros de que el ejercer ese cargo requiere de un alto grado de seguridad en sí mismos, ya que quienes son efectivos líderes del cambio tienen un alto grado de influencia, compromiso, motivación, iniciativa y optimismo; es decir, conoce lo que sucede a su alrededor y está siempre atento a cualquier situación tensa que se pueda presentar, además, de que colabora con sus compañeros y compañeras a construir un ambiente sano y óptimo para el buen funcionamiento institucional.

\section{Referencias}

Dilts, R. (1998). Liderazgo creativo. Ediciones Urano, Barcelona.

Cooper, R. (2003). Con el corazón en el cerebro. Periódico La Nación, Revista Viva, páginas 1, 2.

Donelly, J. (2000). Fundamentos de dirección y administración de empresas. $8^{a}$ edición, Mac Graw Hill.

Goleman, D. (1996). La inteligencia emocional. Editorial Javier Vergara, Buenos Aires.

Goleman, D. (1999). La inteligencia emocional en la empresa. Editorial Javier Vergara, Buenos Aires.

Reigh, E. (2004). Liderazgo emocionalmente inteligente. México, Mc Graw Hill Interamericana. 